\section{Kastamonu Eğitim Dergisi Kastamonu Education Journal}

Kasım 2019 Cilt:27 Sayı:6

kefdergi.kastamonu.edu.tr
Başvuru Tarihi/Received: 21.12.2018

Kabul Tarihi/Accepted: 14.02.2019

DOI: $10.24106 /$ kefdergi.3489

\title{
Lise Öğrencilerinin Bilişsel Esnekliklerinin Cinsiyetlerine ve Mizah Tarzlarına Göre İncelenmesi ${ }^{1}$
}

\section{Investigation of High School Students' Level of Cognitive Flexibility in Terms of Gender and Humor Styles}

\section{Öz}

\author{
Ruveyde AKTEPE ${ }^{2}$
}

Bu çalışmanın amacı, lise öğrencilerinin bilişsel esneklik düzeyleri ile mizah tarzları arasındaki ilişkinin incelenmesidir. Bu amaçla araştırmaya 402 lise öğrencisi katılmıştır. Araştırmada veri toplama aracı olarak Bilişsel Esneklik Ölçeği ve Mizah Tarzları Ölçeği kullanılmıştr. Araştırmada lise öğrencilerinin bilişsel esneklik düzeyleri ile katılımcı mizah tarzları arasında ve bilişsel esneklik düzeyleri ile kendini geliştirici mizah tarzları arasında pozitif yönde anlamIı bir ilişki bulunurken; bilişsel esneklik düzeyleri ile saldırgan mizah tarzları arasında negatif yönde anlamlı bir ilişki bulunmuştur. Araştırma sonucunda lise öğrencilerinin bilişsel esneklik düzeyleri ve kendini geliştirici mizah tarzlarının cinsiyet değişkenine göre anlamlı bir farklılık göstermediği görülmüştür. Araştırmada katlımcı mizah tarzının kız öğrenciler lehine anlamlı düzeyde farklılaştğı sonucuna ulaşılırken; saldırgan mizah ve kendini yıkıcı mizah tarzının erkek öğrenciler lehine anlamlı düzeyde farklılaştığı belirlenmiştir. Araştırma bulguları, ilgili literatür çerçevesinde tartş̧ılmış ve öneriler sunulmuştur.

Anahtar Sözcükler: bilişsel esneklik, mizah, mizah tarzları

\section{Abstract}

The aim of this study is to investigate the relationship between cognitive flexibility levels and humor styles of high school students. For this purpose, 402 high school students participated in the study. Cognitive Flexibility Scale and a Humor Styles Scale were used as data collection tools. In the study, while there was a positive correlation between cognitive flexibility levels of high school students with participatory humor and self-enhancing humor styles; there was a significant negative correlation between cognitive flexibility levels and offensive humor styles. The research revealed that the cognitive flexibility levels and self-enhancing humor styles of high school students did not show a significant difference according to the gender variable. In the study, it was concluded that participatory humor style significantly differentiated in favor of female students; offensive humor and self-destructive humor style differed significantly in favor of male students. The findings of the research were discussed within the framework of relevant literature and recommendations were further presented.

Keywords: cognitive flexibility, humor, humor style

1 Bu çalışma, Doç. Dr. Filiz GÜLTEKin danışmanlığında yürütülen "Lise Öğrencilerinin Bilişsel Esneklik Düzeyleri ve Mizah Tarzları Arasındaki Iliş̧inin İncelenmesi" başlıklı yüksek lisans tezinin bir bölümüdür.

2 Milli Eğitim Bakanlı̆̆ı, Eskişehir, Türkiye; https://orcid.org/0000-0002-5635-7602

Atff / Citation: Aktepe, R. (2019). Lise öğrencilerinin bilişsel esnekliklerinin cinsiyetlerine ve mizah tarzlarına göre incelenmesi. Kastamonu Education Journal, 27(6), 2631-2640. doi:10.24106/kefdergi.3489 


\section{Extended Abstract}

Introduction: Adolescence, which is a transition to adulthood, is of critical importance in developmental terms. Geldard and Geldard (2013) stated that the existence of various physiological, biological, psychological and sociological changes during adolescence results in many challenges. However, at some points individuals encounter certain challenges such as making a decision (Sapmaz \& Doğan, 2013). İt is related to how challenging these situations for person, how the person evaluates the situaiton.

Since the way the individual interprets their experiences is reflected in their feelings and behaviors (Wright, Beck, Newman and Liese, 1993); dysfunctional thoughts can cause emotional and behavioral problems (Beck, 1997). Cognitive flexibility is the situation where the individual is aware of the options and appropriate alternatives, is willing to be flexible and adapt to the situation and to feel competent when feeling flexible (Martin \& Rubin, 1995; Martin \& Anderson, 1998; Martin, Anderson \& Thweatt, 1998). The level of cognitive flexibility plays a decisive role in the state of positive or negative being (Diril, 2011). In this context, it is thought that cognitive flexibility will contribute to a more positive assessment of the situations faced by the individual in life.

One of the effective methods of coping with the stress of daily life is humor. Humor can also facilitate adaptation, like cognitive flexibility, when used effectively. No matter how complicated the problem is, using humor can soften the perspective.

Humor which can evaluate the funny and meaningless aspects of life (Uğur, 2007) increases social support and is also beneficial for psychological health (Martin, 2003). It strengthens the ability to cope with stress (Liu, 2012; Martin, 2003). According to the use of humor in daily life, it has different compatible and incompatible styles. While participatory humor enhances social relationships and self-enhancing humor takes place in the compatible category; offensive humor that is used to hurt others and self-destructive humor, that uses humor in a self-absorbing manner, takes place in the incompatible category (Martin, Puhlik-Doris, Larsen, Gray \& Weir, 2003). Compatible humor styles transform individuals into happier individuals when incompatible humor styles can transform individuals into unhappy individuals who cannot overcome difficulties comfortably (Cengiz, Kayhan \& Acet, 2016).

The adolescent, who is trying to be a part of the adult world, should gain the necessary skills and characteristics to get over this period successfully. At this point, cognitive flexibility and humor can be used by considering the roles that facilitate human life. A dysfunctional thinking style and cognitive schemas should be changed to increase the level of cognitive flexibility (Bilgin, 2009a) used in how the individual thinks. In addition, Corey (2008) points out that humor reveals the meaninglessness of certain thoughts which the individual protects without compromise. Flexible thinking can be attained by exiting standard evaluations with humor. What is important here is what type of humor will get you to the desired result. In this sense, it is important to determine the relationship between cognitive flexibility and humor styles.

Method and Findings: This study is a descriptive study in the relational survey model that examines the relationship between high school students' cognitive flexibility levels and humor styles. This research was done with 9th, 10th and 11th grade students in Çifteler, district of Eskişehir in 2016-2017 education year. In this study, the Cognitive Flexibility Scale (CFS) developed by Bilgin (2009b) was used to determine the cognitive flexibility level and Humor Styles Scale (HSS), developed by Martin et. al. (2003) and adapted to Turkish by E.E.Yerlikaya (2003), was used to determine humor styles. The validity and reliability study of the HSS, which was developed on university students, was carried out by N. Yerlikaya (2007).

The result of the study shows a significant negative correlation between cognitive flexibility levels and offensive humor styles. Concurrently, there was a positive correlation between the cognitive flexibility levels of the high school students with the participatory humor styles and between the cognitive flexibility levels and the self-enhancing humor styles.

Conclusion and Discussion: The value judgments of both the individual and society have a decisive role in the emergence of humor. When society and the individuals forming the society encounter an event, they react to it by using their cognitive and emotional schemas. This reaction mostly reveals itself by laughing behavior (Aydın, 2006). Moreover, cognitive variables have an influence on comprehending humor and laughing at humor (Ereyi, 2016). Since the cognitive structure can reveal humor, it may also be determinative in the use of humor styles. Humor styles may change according to the cognitive schemas and cognitive flexibility of the person. For example; if the person has dysfunctional and irrational beliefs and is cognitively rigid, this person may use offensive humor style. Likewise, people with cognitive flexibility and rational beliefs may use compatible forms of humor. In this context, the positive relationship between the level of cognitive flexibility with participatory humor and self-enhancing humor become crucial.

As a result, it is desirable to have a high level of cognitive flexibility and use of participatory humor and self-enhancing humor styles in the compatible category. In this context, parents should be included in cooperation to increase the cognitive flexibility of students. Studies can be done to encourage students to use participatory humor and self-enhancing humor in their social relations and encourage teachers and families to be role models by using positive humor styles. Studies can be planned about the role models of students on humor and what style they may be prone to could be estimated according to their role models. This subject can be included in the developing psycho-education programs. Considering the positive relationship of participatory humor and self-enhancing humor with cognitive flexibility; mutual interaction can be utilized when planning studies to increase the level of cognitive flexibility and to provide compatible humor styles.

Following studies can be conducted with different educational levels to reach more detailed data by expanding the scope of the research. Based on the relationship between cognitive flexibility and humor styles, the predictive relationship between cognitive flexibility and humor styles can be investigated. Humor styles and cognitive flexibility are not instantly gained facts. Both humor styles and cognitive flexibility are gained over a certain period. In this sense, longitudinal studies and comparisons can be made according to developmental periods. 


\section{Giriş}

Çocukluktan erişkinliğe geçiş basamağı olan ergenlik dönemi, pek çok gelişim alanında kritik bir öneme sahiptir. Geldard ve Geldard (2013) ergenlik döneminde fizyolojik, biyolojik, psikolojik ve sosyolojik pek çok değişikliğin olmasının mücadele edilmesi gereken birçok zorluğu da beraberinde getirdiğini belirtmektedir. Kimi zaman da bireyler bir sorun olmamasına rağmen seçim yapma, karar verme vb. gibi durumlarla karşılaşabilmektedir (Sapmaz \& Doğan, 2013). Bu durumların birey için ne kadar zorlayıcı olduğu bireyin durumu nasıl değerlendirdiğiyle ilişkilidir.

Bireyin deneyimlerini yorumlama biçimi, duygu ve davranışlarına yansıdığından (Wright, Beck, Newman \& Liese, 1993); işlevsel olmayan düşünceler, duygusal ve davranışsal sorunlara sebep olabilmektedir (Beck, 1997). Bilişsel esneklik düzeyi bilişlerin pozitif ya da negatif olma durumu üzerinde belirleyici rol oynamaktadır (Diril, 2011). Bu bağlamda; bilişsel esnekliğin, bireyin yaşamda karşılaştı̆ı durumları daha olumlu değerlendirmesine katkı sağlayacağı söylenebilir.

Bilişsel esneklik, bireyin; belli bir durumda seçeneklerin ve uygun alternatiflerin farkında olması, esnek olmaya ve duruma uyum sağlamaya istekli olması ve esnek olabildiği durumlarda kendisini yetkin hissetmesidir (Martin \& Rubin, 1995; Martin \& Anderson, 1998; Martin, Anderson \& Thweatt, 1998). Bilişsel esnekliğin yüksek olması bireyin yaşamdan aldığı doyumun artmasına, daha sağııklı kararlar alabilmesine ve kendini daha yetkin hissetmesine yardımcı olmaktadır (Bilgiç, 2015). Bilişsel açıdan esnek olmayan kişiler ise karşılaşılan durumlarla işlevsel olmayan yolları kullanarak baş etmeye çalıştı̆ından sık sık hata yaparlar (Canas, Fajardo \& Salmeron, 2006). Bilişsel esneklik hem seçenekleri görebilmeyi hem de çözüm üretebilmeyi sağladığından yaşamı keyifli hale getirir. Bilişsel esnekliğin diğer tarafinda yer alan bilişsel katılık ise işlevsel olmayan düşüncelere neden olarak ruh sağlığı problemlerini beraberinde getirmektedir (Ciarrochi, Said \& Deane, 2005).

Günlük yaşamın stresiyle etkili baş etme yöntemlerinden biri de mizahtır. Mizah da etkili kullanıldığında bilişsel esneklik gibi uyum sağlamayı kolaylaştırabilir. Problem ne kadar karmaşık olursa olsun, mizah kullanılarak olaylara bakış açısı yumuşatılabilir. Kişi mizahi bakış açısıyla olumsuz olayları değerlendirerek, daha pozitif düşüncelere sahip olabilir.

Hayatın komik ve anlamsız yanlarına dair değerlendirebilme yetisi olan mizah (Uğur, 2007), sosyal desteği artırır; ayrıca psikolojik sağılık açısından da faydalıdır (Martin, 2003). Algılanan stres düzeyiyle ilişkili olan mizah (Altunkol, 2011), stresle başa çıkma yeteneğini güçlendirerek yaşanan stres düzeyini de azaltır (Liu, 2012; Martin, 2003). Mizahın günlük kullanımına göre uyumlu ve uyumsuz yönlerinin ele alındığı dört farklı mizah tarzı tanımlanmıştır. Katılımcı mizah ve kendini geliştirici mizah tarzları uyumlu kategoride yer alırken; saldırgan mizah ve kendini yıkıcı mizah tarzları uyumsuz kategoride bulunmaktadır (Martin, Puhlik-Doris, Larsen, Gray \& Weir, 2003). Uyumlu mizah tarzları bireyleri daha mutlu birer birey haline dönüştürürken uyumsuz mizah tarzları da mutsuz ve zorlukları rahat bir şekilde aşamayan bireylere dönüştürebilmektedir (Cengiz, Kayhan \& Acet, 2016). Örneğin katlımcı mizah, etkili sosyal ilişkiler kurmayı sağlayarak sosyal desteği artırmaktadır. Kişiler arası bağıı ı̆̆ geliştiren bir tarz olduğu için bireylerin daha uyumlu duygulara sahip olmasını sağlar. Kendini geliştirici mizah tarzını kullanan birey; yaşanan olaylar ne kadar zorlayıcı olursa olsun mizahi bakış açısıyla olayları değerlendirerek, moralini düzeltebilir. Diğer yandan uyumsuz bir mizah tarzı olan saldırgan mizah tarzına sahip birey ise "önce ben" mesajıyla hareket ettiği için diğerlerine yönelik alay etme, küçük düşürme gibi saldırganca davranışlarda bulunur ve insanları kendisinden uzaklaştırır. Öfke gibi olumsuz duygulara yol açan bu mizah tarzı çoğu açıdan kişinin yaşamını zorlaştıır. Aynı şekilde kişiler arası ilişkiler uğruna kendini yerme, aşağılama gibi davranışları içeren kendini yıkııı mizah tarzı da benlik algısında sıkıntı oluşturabileceğinden, birey üzerinde olumsuz etkilere sebep olabilmektedir.

Katılımcı mizah, saldırgan olmayan ve diğerlerine hoşgörüyle yaklaşmayı vurgulayan mizah stilidir. Bu mizah tarzının kişiler arası ilişkileri geliştirici, kabul edici, onaylayıcı ve bağıılı̆ı artırıcı rolleri bulunmaktadır. Kathlımcı mizah; dışadönüklük, neşelilik, benlik saygısı, yakınlık, ilişki doyumu ve olumlu duygularla pozitif bir ilişsiye sahiptir (Martin ve diğ., 2003). Kendini geliştirici mizah tarzına sahip bireyler, mizahı yanlarında başkalarının olmadığı zamanlarda yaşamın zorluklarına, strese, olumsuz duygulara karşı bir başa çıkma aracı olarak kullanma eğilimindedir (Otrar \& Fındıklı, 2014). Kişi, mizahı negatif duyguları azaltmak amacıyla kullanır. Kendini geliştirici mizahı kullanan birey hem kendi psikolojisini korur hem de diğer insanları eğlendirir (Sayar, 2012). Kendini geliştirici mizah tarzı depresyon, kaygı ve nevrotizmle negatif ilişkiliyken; deneyimlere açıklık, benlik saygısı ve psikolojik iyilik durumu ile pozitif ilişkilidir (Martin ve diğ., 2003).

Uyumsuz mizah tarzlarından olan saldırgan mizah tarzı; alay ya da kötü niyetli mizahın aşırı kullanımıdır (Zhao, Kong \& Wang, 2014). Saldırgan mizah tarzı; mizahı, başkaları üzerindeki potansiyel olumsuz etkilerini dikkate almaksızın kullanmayla ilişkilidir. Kişinin söylemekten kendini alamadığı, başkalarını incitecek ya da kendisinden uzaklaştıracak kompulsif mizah ifadelerini içerir. Bu mizah tarzı öfke, düşmanlık ve saldırganlıkla pozitif ilişkiliyken; ilişki doyumu, vicdan ve 
hoşnut olmayla negatif yönde ilişkilidir (Martin ve diğ., 2003). Kendini yıkıcı mizah tarzını benimseyen birey ise, kendi ihtiyaçlarını dikkate almadan mizahı kullanır. Birey, başkalarını güldürmek ve onlarla arasındaki ilişkileri güçlendirmek adına sürekli olarak kendisini mizahi bir yolla kötüleme, yerme gibi davranışlarda bulunur. Kişinin üzgün olduğu anlarda kendi gerçek duygularını inkar edip mutluymuş gibi davranması da bu tarz mizaha örnektir (E.E.Yerlikaya, 2009). Bu mizah tarzı nevrotizm, depresyon ve kaygıyla pozitif ilişkiliyken; ilişkisel doyum, psikolojik mutluluk ve benlik saygısı ile negatif yönde ilişkilidir (Martin ve diğ., 2003).

Ergenlik, çocuğun genç yetişkinliğe geçmesini sağlayan insan yaşamının bir dizi karmaşık yaşam görevleriyle yüklü dönemidir. Ergenlerden, erinliğin fizyolojik değişimleriyle başa çıkmaları, gelişen bilişsel yapıyı yaşamdan edindikleri tecrübelerle bir bütün haline getirmeleri, ana babadan bağımsızlaşmaları, hemcinsleri ve karşı cinsten yaşıtlarıyla olumlu sosyal ilişkiler kurmaları, akademik anlamda başarı sergilemeleri, mesleki hedef belirlemeleri ve yetişkin rollerine rehberlik edecek değerleri geliştirmeleri beklenmektedir (Öngen, 2002). Yetişkin dünyasının parçası olmaya çalışan ergene, bu dönemi başarıyla atlatabilmesi için gerekli beceri ve özellikler kazandırılmalıdır. Bu noktada insan yaşamını kolaylaştırıcı rolleri göz önünde bulundurularak bilişsel esneklik ve mizahtan yararlanılabilir. Bireyin düşünme sürecini etkileyen bilişsel esneklik, olumsuz durumlar karşısında bile kişinin bocalamasını önleyerek olayların farklı yönlerini keşfetmeyi sağlar, herhangi bir durum karşısında bireyleri tek bir çözüm ya da seçenekte sıkışıp kalmaktan kurtarır, duygusal ve davranışsal problemlerin yaşanmasını önler. Genel iyilik halini artırıcı özellikleri düşünüldüğünde, bilişsel esneklik insan yaşamı için önemli bir kavramdır.

Bilişsel esneklik üzerine yapılmış çalışmalar incelendiğinde bilişsel esnekliğin algılanan stres düzeyi (Altunkol, 2011); sosyal yetkinlik beklentisi, otoriter anne baba tutumu, problem çözme becerisi (Bilgin, 2009a); öfke (Diril, 2011); bağlanma stilleri, akılcı olmayan inançlar (Gündüz, 2013) gibi değişkenlerle ilişkisi olduğu görülmektedir. Bilişsel esneklik yaşamı etkileyen çoğu kavramla ilişkili olduğundan, bilişsel esneklik düzeyinin yüksek olması bu kavramlarda da gelişme sağlayabilir, yaşanılması muhtemel stres ve kaygı yaratıcı olumsuz olaylarla baş etmeyi kolaylaştrabilir, sosyal uyum düzeyini ve problem çözme becerisini artrrabilir, beklenmedik değişikliklere uyum gösterme sürecini hızlandırabilir, bilişte işlev bozukluğu oluşmasını engelleyebilir. Bilişsel esnekliğin yüksek olması yaşam kalitesini artırdığından bu çalışmanın bilişsel esnekliği geliştirmeye yönelik yapılan çalışmalara katkı sağlayacağı düşünülmektedir.

Kişilerin cinsiyetleri ve cinsiyet rolleri, onların nasıl davrandıklarını, toplum içinde nasıl göründüğünü ve kendilerini nasıl gördüklerini etkileyen yapılardır. İnsanların mizah kullanımında cinsiyetler ve cinsiyet rolleri önem teşkil etmektedir. Toplumlar, cinsiyetlere yönelik birçok davranış rolü belirlemişlerdir. Kadınlık ve erkeklik üzerine atfedilen cinsiyet rolleri ve bu cinsiyet rollerinin özellikleri ne ise kullanılan mizah ve mizah tarzları da ona göre değişmektedir (Avşar, 2008). Bilişsel esneklik ise bilişsel gelişim süreci içinde oluşmakta; kazanılan zihinsel becerilerin işlevselliğine göre de yüksek ya da düşük olabilmektedir. Mizah tarzları kullanımı ve bilişsel esneklik düzeyi bireyden bireye farklılık gösterebilmektedir. Cinsiyet de bireysel farklılıkları oluşturan temel kavramlardan biridir. Bu açıdan cinsiyetin ilgili kavramlarla ilişkisinin ortaya çıkarılması literatüre katkı sağlayabilir.

Bireyin nasıl düşündüğü anlamında da kullanılan bilişsel esneklik düzeyini (Bilgin, 2009a) artırmak için işlevsel olmayan düşünce tarzı ve bilişsel şemalar değiştirilmelidir. Bunun yanı sıra Corey (2008) mizahın, bireyin hiç taviz vermeden koruduğu belirli düşüncelerin anlamsızlığını ortaya koyduğunu belirtir. Mizah ile standart değerlendirmeler yerine, esnek düşüncelere ulaşılabilir. İşlevsel olmayan düşüncelerle etkili baş etmede, mizahtan yararlanılabilir. Ancak hangi mizah tarzının kullanıldığı önemlidir. Mizah tarzlarının her birinin kişide ve çevresinde yarattğı etkiler farklılaşmaktadır. Bu sebeple mizah tarzlarının bilişsel esneklikle olan ilişkisini belirlemek önem kazanmaktadır. Bu kapsamda araştırmanın amacı, lise öğrencilerinin bilişsel esneklik düzeyleri ile mizah tarzları arasındaki ilişkinin incelenmesidir. Araştırmanın genel amacı çerçevesinde şu sorulara yanıt aranmıştır:

1. Lise öğrencilerinin Bilişsel Esneklik Ölçeği'nden aldıkları puanlar cinsiyetlerine göre farklılaşmakta mıdır?

2. Lise öğrencilerinin mizah tarzları cinsiyetlerine göre farklılaşmakta mıdır?

3. Lise öğrencilerinin bilişsel esneklik düzeyleri ile mizah tarzları arasında anlamlı bir ilişki var mıdır?

\section{Yöntem}

Bu çalışma, lise öğrencilerinin bilişsel esneklik düzeyleri ile mizah tarzları arasındaki ilişkiyi inceleyen ilişkisel tarama modelinde betimsel bir araştırmadır. iliş̧kisel tarama modeli; değişkenler arasında ilişkinin olup olmadığını veya değişkenlerin düzeylerine göre farklııı olup olmadığını belirlemeye yöneliktir (Erkuş, 2017).

|Kastamonu Eğitim Dergisi, 27(6), 2019| 


\section{Çalışma Grubu}

Bu çalışma 2016-2017 eğitim öğretim yılında Eskişehir ili Çifteler ilçesinde ortaöğretim 9, 10 ve 11. sınıfa devam eden öğrencilerle gerçekleştirilmiştir. Veri toplama işlemi üniversite giriş sınavına yakın bir zamanda yapılmıştır. Üniversite sınavına hazırlandıkları için bu dönemde okula devam etmemeleri ihtimali nedeniyle 12. sınıf öğrencileri çalışmaya dâhil edilmemiştir.

\section{Veri Toplama Araçları}

Bu araştırmada bilişsel esneklik düzeyini belirlemek amacıyla Bilişsel Esneklik Ölçeği ve mizah tarzlarını belirlemek amacıyla Mizah Tarzları Ölçeği kullanılmıştır.

\section{Bilişsel Esneklik Ölçeği (BEÖ)}

Bilgin (2009b) tarafindan geliştirilen ölçeğin maddeleri "yaparım, yapamam, "başarılıyım, başarısızım" gibi sıfat çiftlerinden oluşmaktadır. Ölçek maddelerine yanıt veren birey hangi sıfat kendisine daha yakın hissediyorsa, o sıfata yakın seçeneklerden birini işaretlemektedir. 19 maddeden oluşan ölçekten alınabilecek en yüksek puan 95 iken, en düşük puan 19'dur. BEÖ'den alınan puanların artması, bireyin bilişsel esnekliğe daha çok yaklaştı̆ııı göstermektedir. BEÖ, semantik farklıııklar ölçeklerinin üç boyutunun yapısına paralel olarak hazırlanmıştır. 19 maddelik BEÖ'deki üç faktör, toplam varyansın \%51,33' nü açıklamaktadır. Ölçeğin diğer geçerlik çalışmasında ise, ölçüt geçerliği Fonksiyonel Olmayan Tutumlar Ölçeği kullanılarak yapılmış ve iki ölçek arasındaki korelasyon -,44 olarak saptanmıştır. Ölçek üzerinde yapılan güvenirlik çalışmalarında, ölçeğin bütünü için bulunan Cronbach katsayısının ,92; ölçeğin maddelerinin madde-toplam korelasyonlarının ise ,49 ile ,63 arasında olduğu bulunmuştur. Testin tekrarı yöntemi kullanılarak bulunan korelasyon katsayısının ,77; testi yarılama yöntemiyle hesaplanan güvenirlik katsayısının ise ,87 olduğu saptanmıştır (Bilgin, 2009b).

\section{Mizah Tarzları Ölçeği (MTÖ)}

MTÖ, mizahın günlük kullanımındaki bireysel farklılıklarına ilişkin dört temel boyutu ölçmek amacıyla Martin ve diğ. (2003) tarafindan geliştirilen ve E.E.Yerlikaya (2003) tarafindan Türkçeye uyarlanan bir kendini değerlendirme ölçeğidir. MTÖ, ikisi uyumlu (katılımcı mizah-kendini geliştirici mizah) ve ikisi uyumsuz (saldırgan mizah-kendini yıkıcı mizah) olmak üzere dört farklı mizah tarzını ölçmeyi amaçlayan alt ölçeklerden oluşmaktadır. MTÖ'de 'Tamamıyla Katılıyorum' ile 'Kesinlikle Katılmıyorum' arasında değişen yedili likert tipi bir derecelendirme kullanılmaktadır. Her bir alt ölçek 8'er maddeden oluşmakta ve ölçekte ters yönde puanlanan on bir madde bulunmaktadır. Alt ölçeklerin her birinden alınabilecek puanlar 7 ila 56 arasında değişmektedir. Alt ölçeklerden alınan puanların yüksekliği ilgili mizah tarzının kullanım sıklığını göstermektedir.

MTÖ’nün Türkçe'ye uyarlama çalışmasında alt ölçeklere ilişkin elde edilen Cronbach alfa iç tutarlık katsayıları; katılımcı mizah için ,74; kendini geliştirici mizah için ,78; saldırgan mizah için ,69 ve kendini yıkıcı mizah için ,67; toplam puan için ise ,81 olarak hesaplanmıştır. Ölçeğin devamlılık katsayısını saptamak amacıyla yapılan analizlerde test tekrar test korelasyon katsayıları ise katılımcı mizah için ,88; kendini geliştirici mizah için ,82; saldırgan mizah için ,85 ve kendini yıkıcı mizah için ,85; toplam puan için ise ,91 olarak hesaplanmıştır (E.E. Yerlikaya, 2003).

Üniversite öğrencileri üzerinde geliştirilen bu ölçeğin lise öğrencileri üzerinde geçerlik güvenirlik çalışması N. Yerlikaya (2007) tarafindan, 229'u kız 242'si erkek toplam 471 ortaöğretim öğrencisiyle gerçekleştirilmiştir. Veriler üzerinde yapılan faktör analizi sonucunda örnekleme yeterliliği ,79 bulunmuştur. MTÖ’nün dört faktörünün varyansı açıklama düzeyi \% 35,15'tir. Ölçeğin alt ölçeklerine ilişkin elde edilen Cronbach alfa katsayıları; katılımcı mizah ve kendini geliştirici mizah için ,75; saldırgan mizah için ,64 ve kendini yıkıcı mizah için ,63 olduğu bulunmuştur. Ölçüm sonuçlarının zamana karşı güvenirliğini sınamak amacıyla yapılan analizlerde ise test tekrar test korelasyon katsayıları katılımcı mizah için ,88; kendini geliştirici mizah için ,80; saldırgan mizah için ,86 ve kendini yıkıcı mizah için ,89 olarak bulunmuştur.

\section{Verilerin Toplanması}

Öncelikle veri toplanacak okullarda uygulama yapmak için Eskişehir il Milli Eğitim Müdürlüğü’nden izin alınmıştır. Veri toplama işlemi araştırmacı tarafindan yapılmıştır. Toplamda 402 öğrenciye veri toplama araçları uygulanmıştır. Eksik ve hatalı cevaplanmış formlar değerlendirme dışı bırakılmış, 191 kız 177 erkek toplam 368 öğrencinin formları değerlendirilmiştir. 


\section{Verilerin Analizi}

Veri analizi için ilk olarak normallik testi yapılmış; kendini geliştirici mizah tarzı alt ölçeği hariç diğer dağılımlar, parametrik analizleri uygulayabilmek için gerekli şartları taşımadığından non-parametrik teknikler uygulanmıştır.

Elde edilen veriler, eğer aralıklı ölçekli ve normal dağılıma sahipse, bu durumda ortalamaların farkı için $t$ testi yapılır. Bu şartlar altında $U$ testi yapıldığında fazla bir kayıp olmaz; çünkü büyük örneklemler için, $U$ testinin gücü, $t$ testine göre \% 95'tir. Şöyle ki t testinin gücü 100 ise U testinin gücü 95'tir (Kartal, 2006). Bu sebeple normal dağılıma sahip olan kendini geliştirici mizah tarzı alt ölçeği için de nonparametrik testler uygulanmıştır.

Bu bağlamda; lise öğrencilerinin bilişsel esneklik düzeylerinin ve mizah tarzlarının cinsiyet değişkenine göre farklılaşıp farklılaşmadığını belirlemek için Mann Whitney U testi, lise öğrencilerinin bilişsel esneklik düzeyleri ile mizah tarzları arasında anlamlı bir ilişki olup olmadığını belirlemek için Spearman-Brown Sıra Farkları Korelasyon analizi uygulanmıştr. Verilerin değerlendirilmesinde anlamlılık düzeyi .05 olarak belirlenmiştir.

\section{Bulgular}

Bu bölümde lise öğrencilerinin Bilişsel Esneklik Ölçeği ve Mizah Tarzları Ölçeği'ne verdikleri yanıtlar doğrultusunda elde edilen bulgular yer almaktadır.

Lise öğrencilerinin cinsiyetlerine göre Bilişsel Esneklik Ölçeği'nden aldıkları puanlara ilişkin Tablo 1 aşağıda sunulmuştur.

Tablo 1. Lise Öğrencilerinin Cinsiyetlerine Göre Bilişsel Esneklik Puanlarına İlişkin Mann Whitney U-Testi Sonuçları

\begin{tabular}{lccccc}
\hline Cinsiyet & $\mathbf{N}$ & Sıra Ortalaması & Sıra Toplamı & $\mathbf{U}$ & $\mathbf{p}$ \\
\hline Erkek & 177 & 187,55 & 33196,00 & & \\
Kız & 191 & 187,68 & 34700,00 & 16364,00 &, 597 \\
\hline
\end{tabular}

Tablo 1'de görüldüğü gibi, lise öğrencilerinin bilişsel esneklik düzeylerinin cinsiyet değişkenine göre farklılaşıp farklılaşmadığını belirlemek için yapılan Mann-Whitney U testi sonucunda, bilişsel esneklik düzeyinin cinsiyete göre anlamlı bir farklılık göstermediği belirlenmiştir ( $U=16364,00 ; p>, 05)$.

Lise öğrencilerinin cinsiyet değişkenine göre Mizah Tarzları Ölçeği'nden aldıkları puanlara ilişkin Tablo 2 aşağıda sunulmuştur.

Tablo 2. Lise Öğrencilerinin Cinsiyetlerine Göre Mizah Tarzları Puanlarına ilişsin Mann Whitney U-Testi Sonuçları

\begin{tabular}{|c|c|c|c|c|c|c|}
\hline & Cinsiyet & $\mathbf{N}$ & Sıra Ortalaması & Sıra Toplamı & $\mathbf{U}$ & p \\
\hline \multirow{2}{*}{ Katılımcı Mizah } & Erkek & 177 & 163,46 & 28933,00 & \multirow{2}{*}{13180,00} & \multirow{2}{*}{, 000 } \\
\hline & $\mathrm{K} ı \mathrm{z}$ & 191 & 203,99 & 38963,00 & & \\
\hline \multirow{2}{*}{ Kendini Geliştirici Mizah } & Erkek & 177 & 187,55 & 31196,00 & \multirow{2}{*}{16364,00} & \multirow{2}{*}{,597 } \\
\hline & $\mathrm{K} ı \mathrm{z}$ & 191 & 181,68 & 34700,00 & & \\
\hline \multirow{2}{*}{ Saldırgan Mizah } & Erkek & 177 & 207,00 & 36639,50 & \multirow{2}{*}{12920,50} & \multirow{2}{*}{,000 } \\
\hline & $\mathrm{K} ı \mathrm{z}$ & 191 & 163,65 & 31256,50 & & \\
\hline \multirow{2}{*}{ Kendini Yıkıcı Mizah } & Erkek & 177 & 205,15 & 36311,50 & \multirow{2}{*}{13248,50} & \multirow{2}{*}{,000 } \\
\hline & Kız & 191 & 165,36 & 31584,50 & & \\
\hline
\end{tabular}

Tablo 2'de görüldüğü üzere lise öğrencilerinin Mizah Tarzları Ölçeği'nden aldıkları puanların cinsiyet değişkenine göre farklılaşıp farklılaşmadığını belirlemek için yapılan Mann Whitney U testi sonucunda; katılımcı mizah, saldırgan mizah ve kendini yıkıcı mizah tarzının cinsiyete göre anlamlı düzeyde farklılaştğı görülmektedir (Katılımcı mizah tarzı: $U=13180,00$; Saldırgan mizah tarzı: $U=12920,50$; Kendini yıkıcı mizah tarzı: $U=13248,50 ; p<, 05)$. Kendini geliştirici mizah alt ölçeğinden elde edilen puan ortalamalarının cinsiyet değişkenine göre anlamlı bir farklılık göstermediği belirlenmiştir (Kendini geliştirici mizah tarzı: $U=16364,00 ; p>, 05$ ).

Lise öğrencilerinin bilişsel esneklik puanları ile mizah tarzları puanları arasında anlamlı bir ilişki olup olmadığını belirlemek amacıyla yapılan Spearman-Brown Sıra Farkları Korelasyon analizi sonuçları Tablo 3’te verilmiştir. 
Tablo 3. Lise Öğrencilerinin Bilişsel Esneklik Puanları ile Mizah Tarzları Puanları Arasındaki Korelasyon Sonuçları

\begin{tabular}{llccc}
\hline & & $\mathbf{N}$ & $\mathbf{r}_{\mathbf{s}}$ & $\mathbf{p}$ \\
\hline & Katılımcı Mizah & 368 &, $134^{*}$ &, 010 \\
Bilişsel Esneklik & Kendini Geliştirici Mizah & 368 &, $232^{*}$ &, 000 \\
& Saldırgan Mizah & 368 &,$- 159 *$ &, 002 \\
& Kendini Yıkıcı Mizah & 368 &,- 077 &, 139 \\
\hline
\end{tabular}

Tablo 3'te görüldüğü üzere lise öğrencilerinin bilişsel esneklik düzeyleri ile mizah tarzları arasında anlamlı bir ilişki olup olmadığını belirlemek üzere yapılan Spearman-Brown Sıra Farkları Korelasyon analizi sonucunda; lise öğrencilerinin bilişsel esneklik düzeyleri ve katılımcı mizah tarzı puan ortalamaları arasında pozitif yönde $(p<, 05 ; r=, 134)$; bilişsel esneklik düzeyleri ile kendini geliştirici mizah tarzı puan ortalamaları arasında pozitif yönde $(p<, 05 ; r=, 232)$; bilişsel esneklik düzeyleri ile saldırgan mizah tarzı puan ortalamaları arasında negatif yönde $(p<, 05 ; r=-, 159)$ anlamlı ilişki bulunmuştur. Bilişsel esneklik ile kendini yıkıcı mizah tarzı arasındaki ilişkinin anlamlı olmadığı görülmüştür $(p>, 05 ; r=-, 077)$.

\section{Tartışma ve Öneriler}

Araştırma sonucunda lise öğrencilerinin bilişsel esneklik düzeylerinin cinsiyetlerine göre anlamlı bir farklılık göstermediği belirlenmiştir. Araştırma bulguları daha önce yapılmış çoğu araştırmanın bulguları ile paralellik göstermektedir (Akçay Özcan, 2016; Bilgiç, 2015; Çelikkaleli, 2014; Diril, 2011; Martin \& Rubin, 1995; Öz, 2012; Zong ve diğ., 2010). Öte yandan Altunkol (2011) ise üniversite öğrencileriyle yaptığı çalışmasında bilişsel esnekliğin cinsiyete göre anlamlı bir farklılık gösterdiği sonucuna ulaşmıştır.

Bilişsel esneklik konusunda yapılan çalışmalar incelendiğinde; bilişsel esnekliği yordayan değişkenlerin sosyal yetkinlik beklentisi, otoriter anne baba tutumu, problem çözme becerisi (Bilgin, 2009a); eleştirel düşünme, sözel yaratıcılık, şekilsel yaratıcılık, stresle başa çıkma ve stresle başa çıkmanın alt boyutları olan soruna yönelme ve sosyal destek arama olduğu görülmektedir (Çuhadaroğlu, 2013). Bilişsel esneklik bireyin bilişsel süreçlerini ve bilişsel yapısını temel almaktadır. Kişi, çevreden gelen olumlu ve olumsuz etkilere; cinsiyet bağlamından ayrı olarak, bilişsel alt yapısının gelen malzemeleri nasıl değerlendirdiğine göre tepki verir. Dolayısıyla esas olanın bilişsel süreçler olması sebebiyle, lise öğrencilerinin bilişsel esneklik düzeyleri arasında cinsiyet değişkenine göre farklıık ortaya çıkmamış olabilir.

Araştırmada kathlımcı mizah tarzının kız öğrenciler lehine anlamlı düzeyde farklılaştığı sonucuna ulaşııırken; saldırgan mizah ve kendini yıkıcı mizah tarzının erkek öğrenciler lehine anlamlı düzeyde farklılaştığı belirlenmiştir. Kendini geliştirici mizah tarzı puanlarında, cinsiyet değişkenine göre anlamlı bir farklılık olmadığı görülmüştür. Araştırma bulguları ve literatür incelendiğinde genel olarak kız öğrencilerin daha çok mizahın sağlıklı ve uyumlu tarzlarını kullandığı, erkek öğrencilerin ise daha çok hem kendileri hem de diğerleri için olumsuz sonuçları olan sağıkssı ve uyumsuz mizah tarzlarını kullandıkları söylenilebilir. Akyol (2011) katılımcı mizah tarzında kız öğrencilerin, saldırgan mizah tarzında ise erkek öğrencilerin lehine anlamlı farklılık olduğu bulgusuna ulaşmıştır. Didin (2016), katılımcı ve kendini geliştirici mizah alt ölçeklerinde kız öğrencilerin; saldırgan mizahta ise erkek öğrencilerin ortalamalarının anlamlı düzeyde daha yüksek olduğu sonucuna varmıştr. Cann, Norman, Welbourne ve Calhaun (2008), Chen ve Martin (2007), Martin ve diğ. (2003), N. Yerlikaya (2007) erkeklerin daha fazla saldırgan mizah ve kendini yıkıcı mizah tarzlarını kullandığı sonucuna ulaşmıştır. Soyaldın (2007) uyumlu mizah tarzlarını kızların daha fazla kullandığı; uyumsuz mizah tarzlarını ise erkeklerin daha fazla kullandığı sonucunu elde etmiştir.

Avşar (2008) tarafindan öğretmen adaylarıyla yapılan araştırmada katılımcı, kendini geliştirici ve saldırgan mizah tarzları ile toplumsal cinsiyet rolleri arasında anlamlı bir ilişki bulunmuştur. Cinsiyet ve cinsiyet rolleri mizah tarzları üzerinde belirleyici bir etkiye sahiptir (Kotthoff, 2006; akt., Avşar, 2008). Cinsiyet rollerinin kültürümüzdeki karşlıklarına bakacak olursak; kadınsılık sıklıkla hassasiyet, anlayış, duygusallık, bağımlıık özellikleriyle; erkeksilik ise liderlik, baskınlık, bağımsızlık gibi özelliklerle karakterize edilmiştir (Didin, 2016). Bu açıdan hoşgörülü, ağırbaşlı, anlayışlı olma vb. özellikleri desteklendiği; baskınlık, saldırganlık vb. özellikleri hoş karşılanmadığı için kız öğrenciler günlük yaşamlarında hoşgörü, neşeli olma, benlik saygısı ve psikolojik iyilik durumuyla pozitif ilişkili olan mizahın uyumlu tarzlarını kullanıyor olabilir. Benzer şekilde toplumun erkeklere yüklediği daha saldırgan ve baskın olma özellikleri, onların öfke ve düşmanlık duygularını içeren, kişiler arası ilişkileri zedeleyen mizahın uyumsuz tarzlarını tercih etme sebebi olabilir. Ayrıca daha önce de değinildiği gibi bilişlerimizin duygu ve davranışlarımız üzerinde etkisi bulunmaktadır. Birey, cinsiyetine yönelik algıladığı mesajları bilişsel şemalarına yerleştirdiyse, kullanacağı mizah tarzında bunun etkisini görebiliriz. 
Araştırma sonucunda lise öğrencilerinin bilişsel esneklik düzeyleri ile kathlımcı mizah tarzları arasında ve bilişsel esneklik düzeyleri ile kendini geliştirici mizah tarzları arasında pozitif yönde anlamlı bir ilişki bulunurken; bilişsel esneklik düzeyleri ile saldırgan mizah tarzları arasında negatif yönde anlamlı bir ilişki bulunmuştur. Bilişsel esneklik düzeyi ile kendini yıkıcı mizah tarzı arasındaki ilişkinin anlamlı olmadığı görülmüştür.

Bilişsel esneklik uyumlu ve olumlu kişilerarası ilişkilerin kurulmasına katkıda bulunmaktadır (Bilgin, 2009a). Sosyal ilişkileri geliştirmede önemli rolü bulunan katılımcı mizah tarzının dışadönük olmayla, neşelilik haliyle, benlik saygısıyla, yakınlıkla, ilişki doyumuyla ve olumlu duygularla ilişkisi bulunmaktadır (Martin ve diğ., 2003). Uyum düzeyi arttkç̧a bilişsel esneklik düzeyi artmakta (Öz, 2012); karşılıklı ilişkilerde bağııık ile bilişsel esneklik arasında pozitif ilişki bulunmaktadır (Martin \& Rubin, 1995). Yani, bilişsel esnekliğin yüksek olması da katılımcı mizah kullanımı da sosyal ilişkileri olumlu boyuta taşıyabilmektedir. Bu bilgiler, araştırmanın bulgularından kişiler arası ilişkileri geliştirici, saldırgan olmayan ve hoşgörüyü vurgulayan katılımcı mizah tarzının, sosyal uyumla yakından ilişkisi olan bilişsel esneklik ile arasında pozitif ilişki olmasını desteklemektedir.

Katlımcı mizah gibi uyumlu mizah tarzlarından olan kendini geliştirici mizah tarzı olumsuz durumlarla baş etmek için kullanılır (Otrar \& Fındıklı, 2014). Öz (2012) tarafından yapılan çalışmada kaygı düzeyi azaldıkça bilişsel esneklik düzeyinin arttğı sonucuna ulaşılırken; E.E.Yerlikaya (2009) sağlıklı mizah tarzları (katlımcı ve kendini geliştirici mizah tarzları) ile algılanan stres, kaygı ve depresyon arasında negatif ilişki olduğu yönünde bulgulara ulaşmıştı. Algılanan stres düzeyi (Altunkol, 2011) ve problem çözme becerisi (Bilgin, 2009a) ile ilişkili olan bilişsel esneklik; kendini geliştirici mizahla benzer şekilde stres yaratan durumlarla olumlu başa çıkmayı sağlamaktadır. Stresli durumlarla baş etmek ve olumsuz duyguları azaltmak amacıyla kullanılan kendini geliştirici mizah tarzı ile stresli durumlarda alternatiflerin farkında olmayı ve çözüme ulaşmayı sağlayan bilişsel esneklik arasında anlamlı ilişki çıkması, literatürle paralellik göstermektedir.

Bilişsel Davranışçı Yaklaşım, bilişsel süreçlerimizin dışarıdan gelen etki ve dışarıya verilen tepki arasında önemli bir rolü olduğunu savunur. Bu kurama göre mesaj tehdit içermese bile, birey bilişsel şemalarının etkisiyle mesaja tehdit unsurunu ekleyebilmektedir. Bunun sonucunda ise saldırgan davranışlar görülebilmektedir (Huesmann, 1988; akt., Kıııçarslan, 2009). Kişinin şemalarında saldırgan temaların olması, olayları ve kişileri olumsuz bakış açısıyla değerlendirmesine sebep olabilir. Bilişsel esnekliğin sağlanamadığı durumlarda kişi bu şemaların etkisiyle olaylara farklı açılardan bakamayıp saldırgan davranışlara yönelebilir. Bilişsel esnekliğin sözel saldırganlıkla negatif ilişkisi (Martin ve diğ., 1998) olduğu da göz önünde bulundurulursa bilişsel esneklik düzeyinin düşük olduğu durumlarda kişinin uyumsuz mizah tarzı olan saldırgan mizah tarzını tercih ettiği söylenilebilir.

Elde edilen bulgulara göre bilişsel esneklik ile kendini yıkıcı mizah tarzı arasındaki ilişkinin anlamlı olmadığı görülmüştür. Bilişsel esnekliğe sahip bireyler, girişken, sorumluluk sahibi ve yaşadıklarını anlamlandırabilen bireylerdir. Benzer şekilde özdenetim özelliğine sahip bireyler de öz-disiplinli ve sorumluluk sahibi kişilerdir (Bilgin, 2017). Yetkinlik inancıyla ilişkili olan bilişsel esnekliğin (Bilgin, 2009a; Çelikkaleli, 2014; Martin \& Anderson, 1998); özdenetim ile pozitif bir ilişkisi bulunmakta; bireyin özdenetim özelliği geliştikçe bilişsel esneklik düzeyi de artmaktadır (Bilgin, 2017). Özdenetim düzeyi düşük olan bireyler ise kendini yıkıcı mizah tarzını daha fazla kullanmaktadır (Akdur, 2014). Kendini yıkıcı mizah tarzının stresle başa çıkma tarzlarından boyun eğici yaklaşım ile pozitif ilişkisi düşünüldüğünde (N.Yerlikaya, 2007); bu mizah tarzını kullanan bireylerin olumsuz yaşantılarla etkili bir şekilde baş edemediği, sağılısız başa çıkma yöntemlerini kullandığı söylenilebilir. Bu anlamda aralarında ilişki çıkmamış olması, bilişsel esnekliğin yetkinliği, öz denetimi, etkili baş edebilmeyi beraberinde getirmesiyle ilgili olabilir.

Mizahın ortaya çıkışında hem bireyin hem de toplumun değer yargıları belirleyici bir role sahiptir. Toplum ve onu oluşturan bireyler, herhangi bir olayla karşılaştklarında kendi bilişsel ve duygusal şemalarını kullanarak bir tepki verirler. Bu tepki ise çoğunlukla kendini gülme davranışıyla gösterir (Aydın, 2006). Ereyi (2016) tarafindan ulaşılan sonuçlar da bilişsel değişkenlerin mizahı kavrama ve mizaha gülme üzerindeki rolünü göstermektedir. Özetle bilişsel yapı mizahı ortaya çıkarabildiği gibi mizah tarzlarının kullanımında da belirleyici olabilir. Kişinin sahip olduğu bilişsel şemalarına ve bilişsel esnekliğine göre mizah tarzları değişebilir. Örneğin; kişi, işlevsel olmayan düşünce ve mantık dışı inançlara sahip ve bilişsel olarak katı ise uyumsuz bir mizah tarzı olan saldırgan mizah tarzını kullanıyor olabilir. Aynı şekilde bilişsel olarak esnek ve akılcı inançlara sahip kişiler de uyumlu mizah tarzlarını kullanıyor olabilir. Bu bağlamda bilişsel esneklik düzeyi ile katılımcı mizah ve kendini geliştirici mizah tarzları arasındaki pozitif ilişki önem kazanmaktadır.

Sonuç olarak bilişsel esneklik düzeyinin yüksek olması ve uyumlu kategoride yer alan katlımcı mizah ve kendini geliştirici mizah tarzlarının kullanımı istenen bir durumdur. Okul psikolojik danışmanları, öğrencilerin bilişsel esneklik düzeylerinin artırılması için veli ve öğretmenlere müşavirlik yapılabilir. Bilişsel esnekliğin geliştirilmesi ve akılcı düşünmenin kazandırıması adına yapılacak çalışmalarda, uyumlu mizah tarzlarını içeren etkinlikler hazırlanabilir. Öğretmenlerin ve 
ailelerin; öğrencileri kişiler arası etkileşimlerde uyumlu mizah tarzlarını tercih etmeleri konusunda teşvik etmeleri ve cesaretlendirmeleri doğrultusunda çalışmalar yapılabilir. Bilişsel esnekliğin artırılması ve uyumlu mizah tarzlarının benimsenmesi adına bilgilendirme çalışmaları ve psikoeğitim programları yapılabilir. Öğrencilerin mizah konusundaki rol modelleriyle ilgili çalışmalar planlanabilir. Öğrencilerin model aldıkları kişilere göre de hangi tarza eğilimli olabilecekleri konusunda fikir edinilebilir. Geliştirilecek psikoeğitim programlarında ve yapılacak çalışmalarda kadın ve erkek rol modellerine ilişkin etkinlikler ya da oturumlar hazırlanabilir.

Bu çalışma, Eskişehir ilinin Çifteler ilçesinde 9, 10 ve 11. sınıfa devam eden lise öğrencileriyle yapılmıştır. Öğrencilerin aynı ilçede yaşamalarından ve benzer sosyal ilişkiler içinde olmalarından dolayı ortak yaşantılar geçirme ihtimalleri bulunmaktadır. Bu durum araştırmanın sınırlııklarından biridir. Bilindiği gibi bilişsel esneklik ebeveyn tutumları, sosyal ilişkiler vb. ile ilişkilidir. Bu açıdan farklı özelliklere sahip bölge, şehir ve ilçelerde yapılacak çalışmalar planlanarak, karşılaştırma yapılabilir. Kültürel ve yerel özelliklerin bilişsel esneklik düzeyine etkisi incelenebilir. Ayrıca araştırmanın kapsamı genişletilerek farklı eğitim kademeleriyle benzer çalışmalar yapılabilir. Bilişsel esneklik ile mizah tarzları arasındaki ilişkiden hareketle, bilişsel esneklik ve mizah tarzları arasındaki yordayıcı ilişki araştrılabilir. Mizah tarzları ve bilişsel esneklik bir anda kazanılıp biten olgular değildir. Hem mizah stilleri hem de bilişsel esneklik belli bir süreçte kazanılmaktadır. Bu anlamda boylamsal çalışmalar ile gelişim dönemlerine göre karşılaştırmalar yapılabilir.

\section{Kaynakça}

Akçay Özcan, H. D. (2016). Ergenlerde bilişsel esneklik ile özyeterlik arasındaki ilişkinin incelenmesi (Yayımlanmamış yüksek lisans tezi). Toros Üniversitesi Sosyal Bilimler Enstitüsü, Mersin.

Akdur, S. (2014). Kişilik özellikleri ile psikolojik belirtiler arasındaki ilişkide kişilerarası ilişki tarzları ve mizah tarzlarının aracı rolü (Yayınlanmamış yüksek lisans tezi). Ankara Üniversitesi Sosyal Bilimler Enstitüsü, Ankara.

Akyol, Ü. (2011). Ergenlerde iletişim becerilerinin yordayıcıları olarak öz-duyarlıık ve mizah tarzları (Yayımlanmamış yüksek lisans tezi). Muğla Sıtkı Koçman Üniversitesi Eğitim Bilimleri Enstitüsü, Muğla.

Altunkol, F. (2011). Üniversite öğrencilerinin bilişsel esneklikleri ile algılanan stres düzeyleri arasındaki ilişkinin incelenmesi (Yayımlanmamış yüksek lisans tezi). Çukurova Üniversitesi Sosyal Bilimler Enstitüsü, Adana.

Avşar, V. (2008). Öğretmen adaylarının mizah tarzları ve cinsiyet rolleri ilişkisi (Yayımlanmamış yüksek lisans tezi). Marmara Üniversitesi Eğitim Bilimleri Enstitüsü, İstanbul.

Aydın, i. S. (2006). Türkçe derslerinde mizah kullanımının öğrenci tutum ve başarısına etkisi (ïmir ilköğretim 8. sınıf örnekleminde) (Yayımlanmamış doktora tezi). Dokuz Eylül Üniversitesi Eğitim Bilimleri Enstitüsü, İzmir.

Beck, A. T. (1997). The past and future of cognitive therapy. The Journal of Psychotherapy Practice and Research, 6(4), 276-284.

Bilgiç, R. (2015). Ergenlerin cinsiyet ve öğrenim kademesi düzeylerine göre bilişsel esneklik düzeyleri ile karar stratejileri arasındaki iliş̧inin incelenmesi (Yayımlanmamış yüksek lisans tezi). Çukurova Üniversitesi Sosyal Bilimler Enstitüsü, Adana.

Bilgin, M. (2009a). Bilişsel esnekliği yordayan bazı değişkenler. Çukurova Üniversitesi Eğitim Fakültesi Dergisi, 3(36), 142-157.

Bilgin, M. (2009b). Developing a cognitive flexibility scale: validity and reliability studies. Social Behaviour and Personality, 37(3), 343-354.

Bilgin, M. (2017). Ergenlerin beş faktör kişilik özelliği ile bilişsel esneklik ilişkisi. Elektronik Sosyal Bilimler Dergisi, 16(62), 945-954.

Canas, J. J., Fajardo, I., \& Salmeron, L. (2006). Cognitive flexibility. International Encyclopedia of Ergonomics and Human Factors, 297-300.

Cann, A., Norman, M. A., Welbourne, J. L. \& Calhoun, L. G. (2008). Attachment styles, conflict styles and humor styles: Interrelationships and associations with relationship satisfaction. European Journal of Personality, 22(2), 131-146.

Çelikkaleli, Ö. (2014). Ergenlerde bilişsel esneklik ile akademik, sosyal ve duygusal yetkinlik inançları arasındaki ilişki. Eğitim ve Bilim, 39(176), 347-354.

Cengiz, R., Kayhan, M. \& Acet, M. (2016). Beden eğitimi öğretmenlerinin mizah tarzları ile algılanan duygusal bezdirme üzerine araştırma. International Journal of Science Culture and Sport, 4(2), 490-501.

Ciarrochi, J., Said, T. \& Deana, F. P. (2005). When simplifying life is not so bad: the link between rigidity, stressful life events and mental health in an undergraduate population. British Journal of Guidance \& Counselling, 33(2), 185-197.

Chen, G. \& Martin, R. A. (2007). A comparison of humor styles, coping humor, and mental health between chinese and canadian university students. International Journal of Humor Research, 20(3), 215-234.

Corey, G. (2008). Psikolojik danışma, psikoterapi kuram ve uygulamaları (T. Ergene, çev.). Ankara: Mentis Yayınclık.

Çuhadaroğlu, A. (2013). Bilişsel esnekliğin yordayıcıları. Cumhuriyet International Journal of Education, 2(1), 86-101.

Didin, E. (2016). Sanat eğitimi alan ve almayan ergenlerin mizah tarzlarının ve kişilerarası problem çözme becerilerinin incelenmesi (Yayımlanmamış yüksek lisans tezi). Ankara Üniversitesi Sağlık Bilimleri Enstitüsü, Ankara.

Diril, A. (2011). Lise öğrencilerinin bilişsel esneklik düzeylerinin sosyodemografik değişkenler ve öfke düzeyi ile öfke ifade tarzları arasındaki ilişki açııından incelenmesi (Yayımlanmamış yüksek lisans tezi). Çukurova Üniversitesi Sosyal Bilimler Enstitüsü, Adana.

| Kastamonu Eğitim Dergisi, 27(6), 2019 | 
Ereyi, B. (2016). Ergenlerde bilişsel esneklik düzeyi ve problem çözme becerisinin mizahı kavramayla ilişkisi (Yayımlanmamış yüksek lisans tezi). Ankara Üniversitesi Eğitim Bilimleri Enstitüsü, Ankara.

Erkuş, A. (2017). Davranış bilimleri için bilimsel araştırma süreci (5. baskı). Ankara: Seçkin Yayıncılık.

Geldard, K. \& Geldard, D. (2013). Ergenler ve gençlerle psikolojik danışma-proaktif yaklaşım (M. Pişkin, çev. ed.). Ankara: Nobel.

Kartal, M. (2006). Bilimsel araştırmalarda hipotez testleri. Ankara: Nobel Yayın Dağıtım.

Kılıçarslan, S. (2009). İlköğretim 7. ve 8. sınıf öğrencilerinin akılcı olmayan inançları ile saldırganlık düzeyleri arasındaki ilişkinin incelenmesi (Yayımlanmamış yüksek lisans tezi). Çukurova Üniversitesi Sosyal Bilimler Enstitüsü, Adana.

Liu, K. W. Y. (2012). Humor styles, self-esteem and subjective happiness. Discovery - SS Student E-Journal, 1, 21-41.

Martin, M. M. \& Rubin, R. B. (1995). A new measure of cognitive flexibility. Psychological Reports, 76, 623-626.

Martin, M. M. \& Anderson, C. M. (1998). The cognitive flexibility scale: three validity studies. Communication Reports, 11(1), 1-9.

Martin, M. M., Anderson, C. M. \& Thweatt, K. S. (1998). Aggressive communication traits and their relationships with the cognitive flexibility scale and the communication flexibility scale. Journal of Social Behavior and Personality, 13(3), $531-540$.

Martin, R. A. (2003). Sense of humor. Positive Psychological Assessment: A Handbook of Models and Measures, 313-326.

Martin, R. A., Puhlik-Doris, P., Larsen, G., Gray, J. \& Weir, K. (2003). Individual differences of uses of humor and their relation to psychological well-being: development of the humor styles questionnaire. Journal of Research in Personality, 37, 48-75.

Otrar, M. \& Fındıklı, E. B. (2014). Okul yöneticilerinin mizah tarzları ile yaşam doyumları arasındaki ilişkinin incelenmesi (Ataşehir örneği). Eğitim Bilimleri Dergisi, 39, 145-157.

Öngen, D. (2002). Ergenlerde sorunlarla başa çıkma davranışları. Eğitim ve Bilim, 27(125), 54-61.

Öz, S. (2012). Ergenlerin cinsiyet, sosyo-ekonomik ve öğrenim kademesi düzeylerine göre bilişsel esneklik, uyum ve kaygı puanları arasındaki ilişkinin incelenmesi (Yayımlanmamış yüksek lisans tezi). Çukurova Üniversitesi Sosyal Bilimler Enstitüsü, Adana.

Sapmaz, F. \& Doğan, T. (2013). Bilişsel esnekliğin değerlendirilmesi: bilişsel esneklik envanteri Türkçe versiyonunun geçerlik ve güvenirlik çalışmaları. Ankara Üniversitesi Eğitim Bilimleri Fakültesi Dergisi, 46(1), 143-161.

Soyaldın, S. Z. (2007). Ortaöğretim öğrencilerinin öfke ifade tarzları ile mizah tarzları arasındaki ilişkinin incelenmesi (Yayımlanmamış yüksek lisans tezi). Mersin Üniversitesi Sosyal Bilimler Enstitüsü, Mersin.

Uğur, İ. (2007). Televizyon reklamlarında mizahın kullanımı (Yayımlanmamış doktora tezi). Selçuk Üniversitesi Sosyal Bilimler Enstitüsü, Konya.

Yerlikaya, N. (2007). Lise öğrencilerinin mizah tarzları ile stresle başa çıkma tarzları arasındaki ilişkinin incelenmesi (Yayımlanmamış yüksek lisans tezi). Çukurova Üniversitesi Sosyal Bilimler Enstitüsü, Adana.

Yerlikaya, E. E. (2003). Mizah tarzları ölçeğinin (humor styles questionnaire) uyarlama çalışması (Yayımlanmamış yüksek lisans tezi). Çukurova Üniversitesi Sosyal Bilimler Enstitüsü, Adana.

Yerlikaya, E. E. (2009). Üniversite öğrencilerinin mizah tarzları ile algılanan stres, kaygı ve depresyon düzeyleri arasındaki ilişkinin incelenmesi (Yayımlanmamış doktora tezi). Çukurova Üniversitesi Sosyal Bilimler Enstitüsü, Adana.

Zhao, J., Kong, F. \& Wang, Y. (2014). Exploring the mediation effect of social support and self-esteem on the relationship between humor style and life satisfaction in chinese college students. Personality and Individual Differences, 64, 126-130.

Zong, J., Cao, X. Y., Cao, Y., Shi, Y. F., Wang, Y. N., Yan, C., et.al. (2010). Coping flexibility in college students with depressive symptoms. Health and Quality of Life Outcomes, 8(66), 1-6.

Wright, F. D., Beck, A. T., Newman, C. F., \& Liese, B. S. (1993). Cognitive therapy of substance abuse: Theoretical rationale. NIDA Research Monograph, 137, 123-146.

| Kastamonu Eğitim Dergisi, 27(6), 2019| 